\title{
Stabilization of CL and CI Soil Using Sugarcane Bagasse Ash and Quarry Dust
}

\author{
Abdul Hudoos $\mathrm{A}^{(1)}$,Dr.Premalatha. $\mathrm{K}^{(2)}$ \\ ${ }^{(1)}$ Assistant Engineer,PWD,Chennai. \\ ${ }^{(2)}$ Professor, Division of Soil Mechanics and Foundation Engineering, Anna University, Chennai.
}

\begin{abstract}
This paper presents the study of potential of bagasse ash with quarry dust to stabilize the clay soil. The evaluation involves the determination of the geotechnical properties of clay $(C L \& C I)$ soil in its natural state and also when mixed with various proportions of bagasse ash with quarry dust. The parameters tested include the specific gravity, particle size distribution, Atterberg's limits, compaction characteristics, California bearing ratio (CBR) and the unconfined compressive strength (UCS). The strength test was repeated after curing period 0 day, 7days, 14days, and 28days of the treated samples. Results reveal that by addition of bagasse ash the geotechnical parameters of clay are improved as free swell index reduced by $89 \%$ for CL type soil and $60 \%$ for CI type soil. UCS increased by $56 \%$ and $11 \%$ for CL and CI type soil respectively. On addition of bagasse ash with quarry dust, soaked CBR increased $87 \%$. Result also shows that curing improves strength of bagasse ash treated clay. These results imply that bagasse ash can be effectively used as an admixture to stabilize the clay soil as an alternative for soil sub grade in pavement of highway.
\end{abstract}

Keywords:- Bagasse Ash, Quarry dust, Soil Stabilization, CL and CI soil.

\section{INTRODUCTION}

The load from any building is transmitted by the foundation to the soil lying underneath it. Structural design is largely influenced by the soil quality. Expansive soils are weak soils which is encountered as substructure for buildings, bridges, embankments etc. The expansive soils experiences change in volume on interaction with water. The soil exhibit swelling during rainy season and shrinks during summer. Expansive soil covers nearly $20 \%$ of the land mass in India. Typical behavior of soil results in failure of structure in the form of settlements cracks. Therefore, it is imperative to evacuate the existing weak soil and supplant it with soil which is non-expansive or refine the properties of weak soil by stabilization. The native properties of the soil are upgraded by soil stabilization by the addition of cementing materials or chemicals. One of the most widely recognized strategies of stabilization incorporates the blending of natural coarsegrained soil and fine-grained soil to acquire a blend that develops sufficient cohesion and internal friction and thereby providing a material that is workable during placement. Stabilization of soil can be done by mechanical stabilization, chemical stabilization and cementing stabilization. Reposition of soil grains by compacting the soil by mechanical means is referred to as Mechanical compaction. Cement stabilization refers to the addition of cementing material such as cement, lime, bitumen/asphalt etc. to soil and Chemical stabilization is the use of chemicals such as calcium chloride; sodium chloride etc. in soil. Today, world faces a difficult issue in discarding the large amount of agricultural waste. Environmental health gets affected when the agricultural waste is disposed without proper attention. Therefore, safe disposal of agricultural waste becomes a massive challenge for the engineers. A threadlike material procured from sugar cane plant after the withdrawal of sugar cane juice is bagasse ash. The bagasse ash is utilized as bio fuel and in mass production of paper. A single lot of crushed sugar cane in the sugarcane industry produces $30 \%$ bagasse. The end product of the burnt bagasse is called "bagasse ash" which exhibits pozzolanic properties due to the presence of amorphous silica. This property assists in improving the shear strength by holding the soil grains together. During the production of coarse aggregates, large sized stones are crushed in crusher units and the resulting by product is called Quarry dust. Bagasse ash and Quarry dust when disposed create a lot of geo environmental problems. The joint utilization of bagasse ash with quarry dust as stabilizing material for clay soil can be checked under various tests such as standard proctor test, unconfined compression test, California bearing ratio test, Atterberg's limit test etc.

\section{PREVIOUS RESEARCH}

Stabilization of expansive soil using a mixture of cementitious substance and agricultural end product is studied by many researchers and some of them are mentioned below.

Kiran and Kiran (2013) conducted laboratory investigation with different proportions of bagasse ash as an additive and determined various strength parameters like unconfined compressive strength and CBR. The density, CBR and unconfined compressive strength values changed when bagasse ash was blended with different percentage of cement/lime for black cotton soil.

Kharade et al (2014) conducted laboratory experiments and studied the effects of bagasse ash on black cotton soil by substituting bagasse ash $(3 \%, 6 \%, 9 \%$ and $12 \%)$. The properties of black cotton soil are improved at $6 \%$ substitution of bagasse ash with no cementing or chemical material. 
Manikandan and Moganraj (2014) studied rebound and consolidation characteristics of expansive soil using bagasse ash and lime. The liquid limit reduces and plastic limit increases with the increase in bagasse ash content with lime. From this, it can be deduced that the flow characteristics of soil sample are gradually decreasing and the increase of plastic limit implies that bagasse ash and lime treated soil required more water to change it from plastic state to semisolid state.

Dang et al (2016) examined the bearing capacity and shrinkage characteristics of expansive soil treated with hydrated lime and bagasse ash. Linear shrinkage and CBR testing reveal that the bearing capacity and strength of stabilized expansive soil improved and the linear shrinkage reduced significantly.

Shimola (2018) carried out experiments by partial replacement of black cotton soil by bagasse ash $(4 \%, 8 \%, 12 \%, 16 \%, 20 \%)$. For $16 \%$ measure of the bagasse ash the maximum dry density, unconfined compressive strength and shear strength were improved.

Athira and Sini (2019) conducted Standard Proctor Compaction test, CBR test and Atterberg limits test on kaolinite clay mixed with bagasse ash in different percentages. An improvement in the strength and index properties was witnessed. Bagasse ash treated kaolinite clay showed an increase of 54\% CBR.

\section{EXPERIMENTAL PROGRAMME}

\section{Materials and its properties}

The soil sample were collected from Taramani and West Mambalam, Chennai at 2.0m depth from ground level by making open trench. The geotechnical properties of the soil sample were determined and are presented in the table1.

\begin{tabular}{|c|c|c|}
\hline Properties & Soil 1 & Soil 2 \\
\hline Specific Gravity, Gs & 2.64 & 2.62 \\
\hline Sand fraction (\%) & 38 & 28 \\
\hline Silt fraction (\%) & 30 & 47 \\
\hline Clay fraction (\%) & 32 & 25 \\
\hline Liquid Limit (\%) & 41 & 34 \\
\hline Plastic Limit (\%) & 19 & 23 \\
\hline Plasticity Index (\%) & 22 & 11 \\
\hline Shrinkage Limit (\%) & 13 & 20 \\
\hline $\begin{array}{c}\text { (\%) Differential Free Swell } \\
\text { Index (DFSI) }\end{array}$ & 71 & 44 \\
\hline $\begin{array}{c}\text { Swell classification based on } \\
\text { DFSI }\end{array}$ & Medium & Low \\
\hline Maximum dry density (g/cm ${ }^{3}$ ) & 1.75 & 1.79 \\
\hline Optimum Moisture Content (\%) & 16.83 & 14 \\
\hline General rating of clay for \\
pavement based on Group Index & Fair to & poor \\
\hline HRB classification & A-7 & poor \\
\hline CBR (Un soaked) (\%) & - & 11.9 \\
\hline CBR (Soaked) (\%) & 1.1 & 1.2 \\
\hline BIS classification (IS 1496- & CI & CL \\
\hline 1971) & & \\
\hline
\end{tabular}

Table 1:- Index Properties of Soil $1 \&$ Soil 2
The chemical properties and Index properties of the Bagasse ash were procured from the manufacturer. Silica ( $\mathrm{SiO} 2)$ is the major chemical element constituting $62.43 \%$ by weight and the other chemical elements present in a fewer percentage are $\mathrm{Fe} 2 \mathrm{O} 3, \mathrm{Al} 2 \mathrm{O} 5$, LOI, K2O, CaO, SO3, $\mathrm{Mn}$, Zinc, $\mathrm{Cu}$. The bagasse ash is non plastic with a specific gravity of 1.62 , maximum dry density of $1.04 \mathrm{~g} / \mathrm{cm}^{3}$ with Optimum moisture content of $40 \%$. It is classified as SPSM as per BIS $1496-1971$.

The different properties of the quarry dust obtained are shown in table 2 .

\begin{tabular}{|c|c|}
\hline Properties & Values \\
\hline Specific Gravity & 2.73 \\
\hline Sand (\%) & 84 \\
\hline Fines (\%) & 16 \\
\hline Maximum dry density $\left(\mathrm{g} / \mathrm{cm}^{3}\right)$ & 1.97 \\
\hline Optimum Moisture Content (\%) & 12 \\
\hline CBR (Un soaked) (\%) & 26 \\
\hline CBR (Soaked) (\%) & 12 \\
\hline
\end{tabular}

Table 2:- Index Properties of Quarry Dust

\section{$>$ Methods adopted}

The experiments were performed on natural soil with increasing percentages of bagasse ash ranging from $0 \%$, $5 \%, 10 \%, 15 \%, 20 \%$ with and without quarry dust. The properties such as free swell index, liquid limit, plastic limit, shrinkage limit, optimum moisture content, maximum dry density, unconfined compressive strength and California bearing ratio values were obtained.

\section{RESULTS AND DISCUSSION}

The variations of liquid limit of CL and CI soil incorporating bagasse ash are indicated in Figure1.

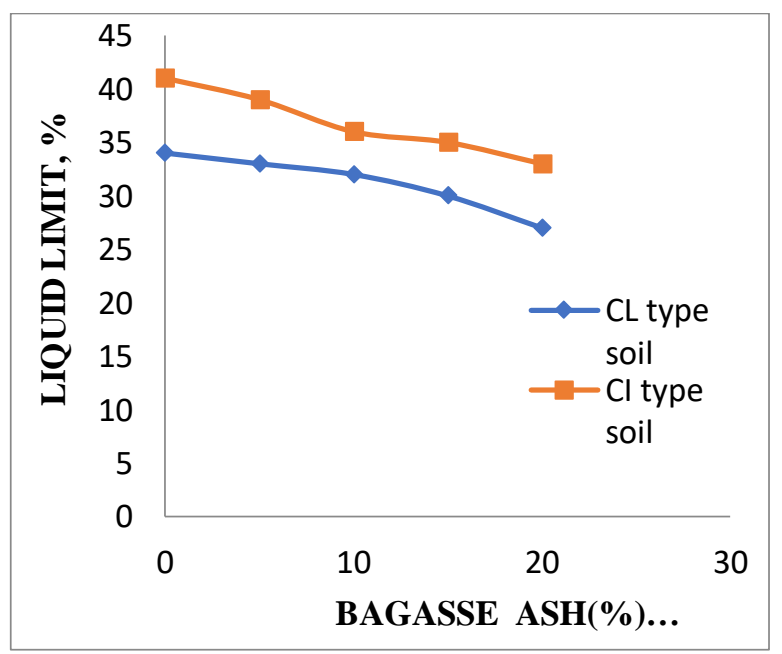

Fig 1:- Effect of Bagasse ash on Liquid limit 
From the above figure it can be observed that for CI type soil $+20 \%$ bagasse ash, the liquid limit has reduced from $41 \%$ to $33 \%$ and the reduction is $20 \%$. For CL type soil $+20 \%$ bagasse ash, the liquid limit reduced from $34 \%$ to $27 \%$ and the reduction is $21 \%$.

The variations of Plastic limit of CL and CI soil incorporating bagasse ash are indicated in Figure 2.

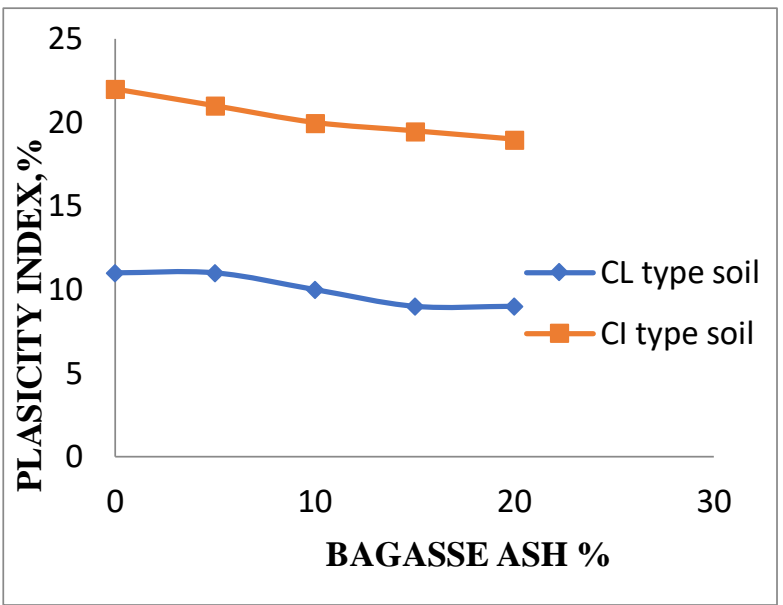

Fig 2:- Effect of Bagasse ash on Plastic limit

From the above figure it can be observed that for CI type soil $+20 \%$ bagasse ash, the plastic limit has reduced from $19 \%$ to $14 \%$ corresponding and the reduction is $26 \%$. For CL type soil $+20 \%$ bagasse ash the plastic limit reduced from $23 \%$ to $16 \%$ and the reduction is $30 \%$.

The variations of Plasticity Index of CL and CI soil incorporating bagasse ash are indicated in Figure 3.

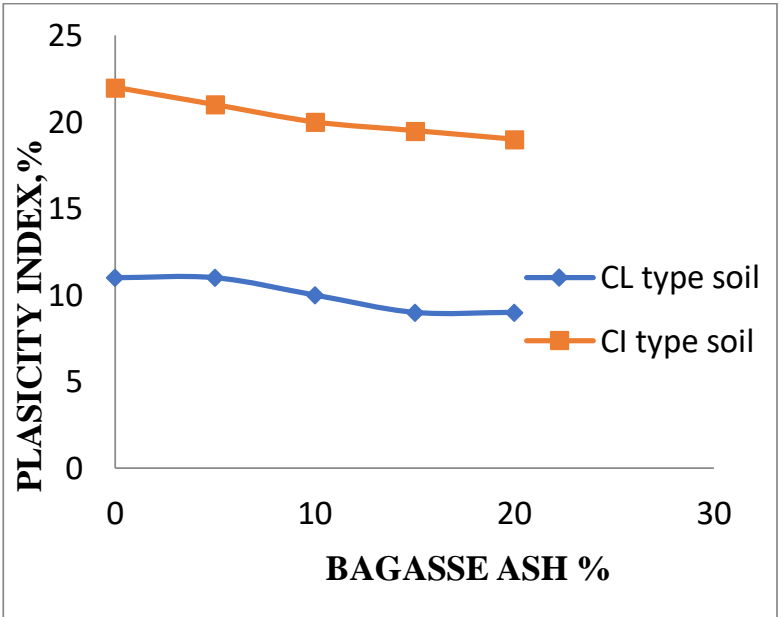

Fig 3:- Effect of Bagasse ash on Plasticity index

From the figure it shows that for CI type soil $+20 \%$ bagasse ash, the plasticity index has reduced from $22 \%$ to $19 \%$ and the reduction is $14 \%$. For CL type soil $+20 \%$ bagasse ash, there is a reduction of plasticity index from $11 \%$ to $9 \%$ and the reduction is $18 \%$.

The variations of free swell index of CL and CI soil incorporating bagasse ash are indicated in Figure 4.

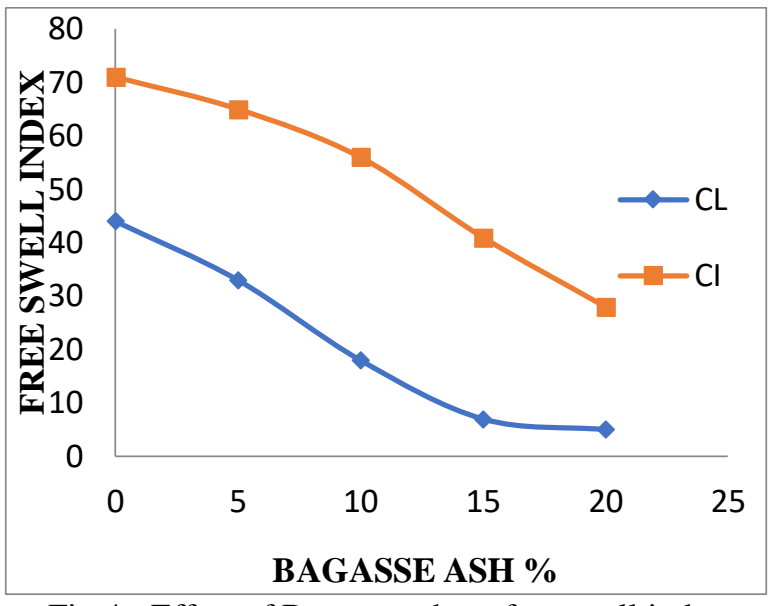

Fig 4:- Effect of Bagasse ash on free swell index

From the figure it is seen that for CI type soil+20\% bagasse ash, the free swell index reduced from $71 \%$ to $28 \%$ and the reduction is $60 \%$. For CL type soil $+20 \%$ bagasse ash, the free swell index reduced from $44 \%$ to $5 \%$ and the reduction is $89 \%$.

The variations of Maximum dry density of CL and CI soil incorporating bagasse ash are indicated in Figure 5.

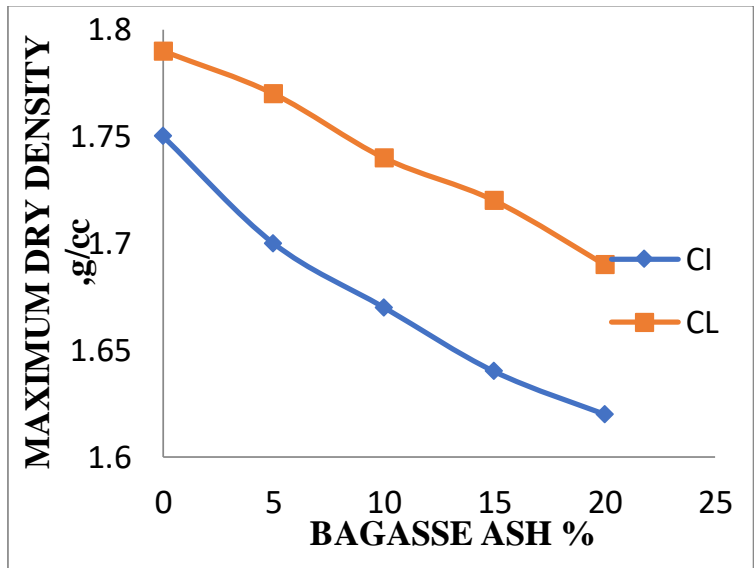

Fig 5:- Effect of Bagasse ash on Maximum dry density

The figure shows that the variation of maximum dry density. For CI type soil $+20 \%$ bagasse ash, a reduction of maximum dry density from $1.75 \mathrm{~g} / \mathrm{cc}$ to $1.62 \mathrm{~g} / \mathrm{cc}$ is witnessed and the reduction is $7 \%$. For CL type soil $+20 \%$ bagasse ash, it reduced from $1.79 \mathrm{~g} / \mathrm{cc}$ to $1.69 \mathrm{~g} / \mathrm{cc}$ and the reduction is $6 \%$.

The variations of Optimum moisture content of CL and CI soil incorporating bagasse ash are indicated in Figure 6. 
ISSN No:-2456-2165

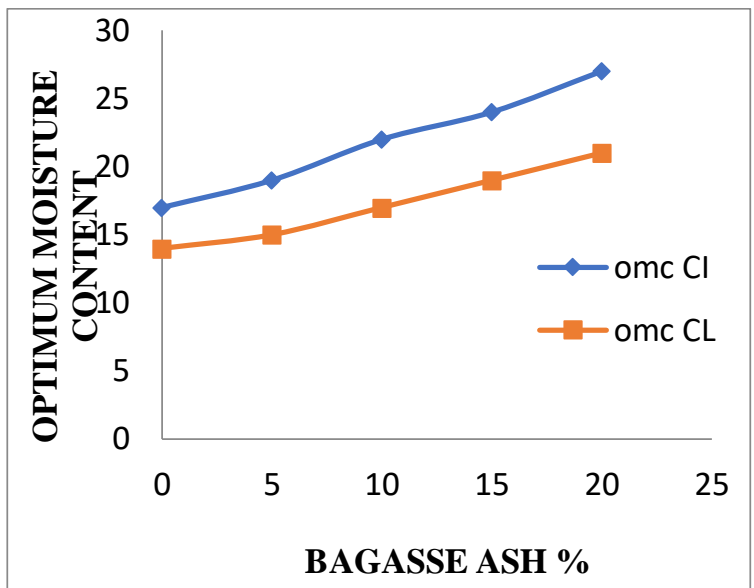

Fig 6:- Effect of Bagasse ash on OMC

The above figure shows that for CI type soil $+20 \%$ bagasse ash, the optimum moisture content (OMC) increases from 17 to 27 and the increment is $37 \%$. For CL $+20 \%$ bagasse ash the OMC increases from 14 to 21 and the increment is $33 \%$.

The variations of UCC strength of CL and CI soil incorporating bagasse ash are indicated in Figure 7.

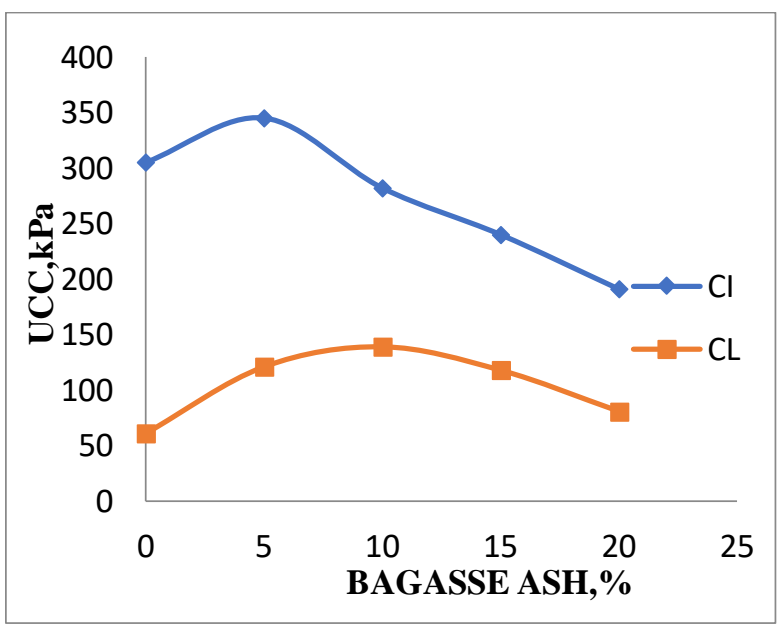

Fig 7:- Effect of Bagasse ash on UCC

From the above figure it is seen that the UCC of soil attains a maximum of $345 \mathrm{kPa}$ when $5 \%$ bagasse ash is added to the soil sample. However, it shows a decreasing compressive strength from $345 \mathrm{kPa}$ to $191 \mathrm{kPa}$ when the bagasse ash increases from $5 \%$ to $20 \%$. The results reveal that the optimum percentage of bagasse ash to stabilize the CI type soil is $5 \%$.

With the increment of bagasse ash, the UCC strength increased from $61 \mathrm{kPa}$ to $139 \mathrm{kPa} .139 \mathrm{kPa}$ is obtained at $10 \%$ addition of bagasse ash to the soil sample which is the maximum. However, it shows decreasing compressive strength from $139 \mathrm{kPa}$ to $81 \mathrm{kPa}$ when the bagasse ash was increased from $5 \%$ to $20 \%$. The results infer that the optimum percentage of bagasse ash is $10 \%$ to stabilize the CL type soil at the maximum strength of $139 \mathrm{kPa}$.

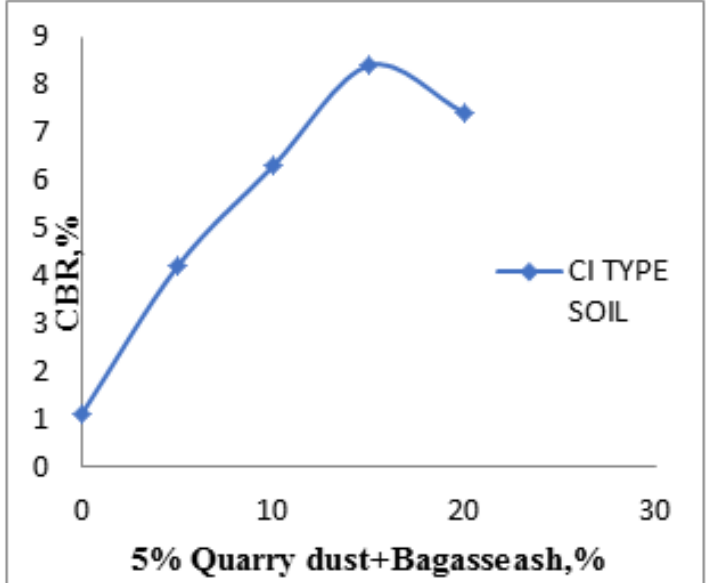

Fig 8:- Influence of 5\%Quarry Dust + Bagasse ash on soaked CBR

From the above figure it shows that the soaked CBR value increased from 1.1 to 8.4 for 5\% Quarry dust and $15 \%$ bagasse ash for CI type soil.

\section{CONCLUSIONS}

The following are the conclusions that can be drawn from the results of the study/investigation carried out within the scope of this study.

$>$ With the rise in proportion of bagasse ash the plasticity index slightly reduced.

$>$ With increment in addition of bagasse ash content the maximum dry density value decreased.

$>$ Free swell index of the stabilized samples decreased with increasing bagasse ash content.

$>\mathrm{CBR}$ values increased with the addition of bagasse ash plus Quarry dust. Addition of bagasse ash alone does not improve the strength of soils due to presence of only reactive silica with low amount of calcium content in bagasse ash.

$>$ The inclusion of bagasse ash alone has minor effect on the plasticity index of expansive soil.

The addition of bagasse ash in combination with Quarry dust improved the CBR value.

\section{REFERENCES}

[1]. Kiran R. G and Kiran L, (2013), "Analysis of Strength Characteristics of Black Cotton Soil Using Bagasse Ash and Additives as Stabilizer", International Journal of Engineering Research \& Technology, Vol.2, Issue 7, pp. 2240-2246.

[2]. Amit S. Kharade, Vishal V. Suryavanshi, Bhikaji S. Gujar and Rohankit R. Deshmukh, (2014), "Waste Product Bagasse Ash from Sugar Industry can be used as Stabilizing Material for Expansive Soils", International Journal of Research in Engineering and Technology, Volume: 3, Issue:3, pp. 506-512.

[3]. Manikandan.A and Moganraj.M, (2014), "Consolidation and Rebound Characteristics of Expansive Soil by Using Lime and Bagasse Ash", International Journal of Research in Engineering and Technology, vol. 03, Issue-04, pp. 403-11. 
[4]. Liet Chi Dang, Hayder Hasan, Behzad Fatahi, Robert Jones and Hadi Khabbaz, (2016), "Enhancing the engineering properties of expansive soil using bagasse ash and hydrated lime", International Journal of GEOMATE, Vol. 11, Issue 25, pp. 2447-2454.

[5]. Shimola K, (2018), "A Study on Soil Stabilization using Sugarcane Bagasse Ash", International Journal of Innovative Technology and Exploring Engineering, Vol. 8, Issue 2S, pp. 292-295.

[6]. Athira T and Sini T, (2019), "Effect of Bagasse Ash on Strength Characteristics and Index Properties of Kaolinite Clay", International Journal of Engineering Research \& Technology, Vol. 8, Issue 06, pp. 12731275. 